\title{
Hydropeaking in regulated rivers - from process understanding to design of mitigation measures
}

\author{
Hauer, C. ${ }^{1}$, Siviglia, A. ${ }^{2}$, Zolezzi, G. ${ }^{3}$
}

${ }^{1}$ Institute for Water Management, Hydrology and Hydraulic Engineering, Department for Water Atmosphere - Environment, BOKU - University of Natural Resources and Life Sciences Vienna, Muthgasse 107, 1190 Vienna, Austria

${ }^{2}$ Laboratory of Hydraulics, Hydrology and Glaciology (VAW) ETH, Zürich Switzerland

${ }^{3}$ Department of Civil, Environmental and Mechanical Engineering, University of Trento, via Mesiano 77, 38123, Trento Italy

Hydropeaking - the artificial increase and decrease of discharge and corresponding water levels in rivers - is characterized by steep rising and falling limbs of hydrographs based on the operation of storage hydropower plants to generate electricity on the energy demand. Scientific attention to this process has started in the early 1980s, as part of the raising awareness that hydro-morphological pressures could be of comparable relevance to pollution in the degradation of river ecosystem health.

Traditionally, the study of hydropeaking has been focusing on its most evident ecological effects, related to stranding and catastrophic drifting of fish and macroinvertebrates downstream of the intermittent water releases from hydropower facilities. Here, the structure and functions of biological communities were often found to be highly altered, causing serious environmental concerns. Besides such direct impacts, however, other effects of hydropeaking on the array of complex processes within the river corridor have gradually emerged to the attention of researchers, river managers, environmental protectionists and hydropower managers too. Hydropeaking may affect river thermal dynamics, sediment composition and transport (e.g. increase in turbidity), habitat distribution and quality, riparian vegetation, but also river water chemical composition as well as the use of rivers for recreation. It is also recognized that many of these causal relations often take the form of mutual feedbacks, rather than representing purely unidirectional effects.

Moreover, besides the direct impacts of the fluctuating discharges on the biota (stranding and drift), other effects on the array of complex processes within the river corridor have to be discussed in a broader perspective, encompassing yet unclear biophysical dynamics related to those artificial flow pulses. Hydropeaking may affect river thermal dynamics, sediment composition and transport (e.g. increase in turbidity), habitat distribution and quality, riparian vegetation. To mitigate such ecological impacts, in various national environmental regulations of European countries, threshold ratios between base $\left(\mathrm{Q}_{\text {base }}\right)$ and peak flow $\left(\mathrm{Q}_{\text {peak }}\right)$ have been established (e.g., Q $\mathrm{Q}_{\text {base }}=33 \mathrm{~m}^{3} \mathrm{~s}^{-1} / \mathrm{Q}_{\text {peak }}=99 \mathrm{~m}^{3} \mathrm{~s}^{-1}$; $\mathrm{Q}_{\text {base }} / \mathrm{Q}_{\text {peak }}=1: 3$ ) with the assumption that the higher such discharge ratio is, the greater the negative impacts on aquatic ecology are. Those assumptions, however, have not been systematically validated from a biophysical, processbased perspective. Biophysical process understanding is limited especially when considering the broad range of affected time scales, from the highly unsteady event-scale to yearly or longer scales affected by hydropeaking repetitiveness.

In Europe, requirements posed by several EU Directives (as the Water Framework, Habitats, Renewables Directives) can often be addressed by seeking unconventional tradeoff solutions that require careful investigations of novel river management and restoration measures, able to optimize river ecosystem services and biodiversity protection. Hydropeaking research is recently witnessing an increased effort from several groups in Europe and worldwide to improve basic knowledge in terms of process understanding, to increase management capacity in terms of the design and testing of suitable mitigation measures, and to strengthen the linkages between basic knowledge and practical applications. 
The aim of the presented special issue on "Hydropeaking" was to synthesize present basic and applied research efforts related to hydropeaking, by inviting research groups that are presently working on the multi-dimensional aspects of the topic. Contributions were welcome in terms of field-based, experimental, modeling and integrated approaches, as well as in terms of meta-analysis, global or regional-scale synthesis, lessons learned from testing of innovative mitigation measures. All interdisciplinary topics clearly related with hydropeaking have been considered, encompassing the Hydrosphere (alteration of surface flow regimes and physical habitats), Biosphere (response of aquatic and riparian biota), Lithosphere (alteration of the sediment transport regimes and changes in river morphology) and Anthroposphere (economic and social relevance of hydropower, recreational water uses).

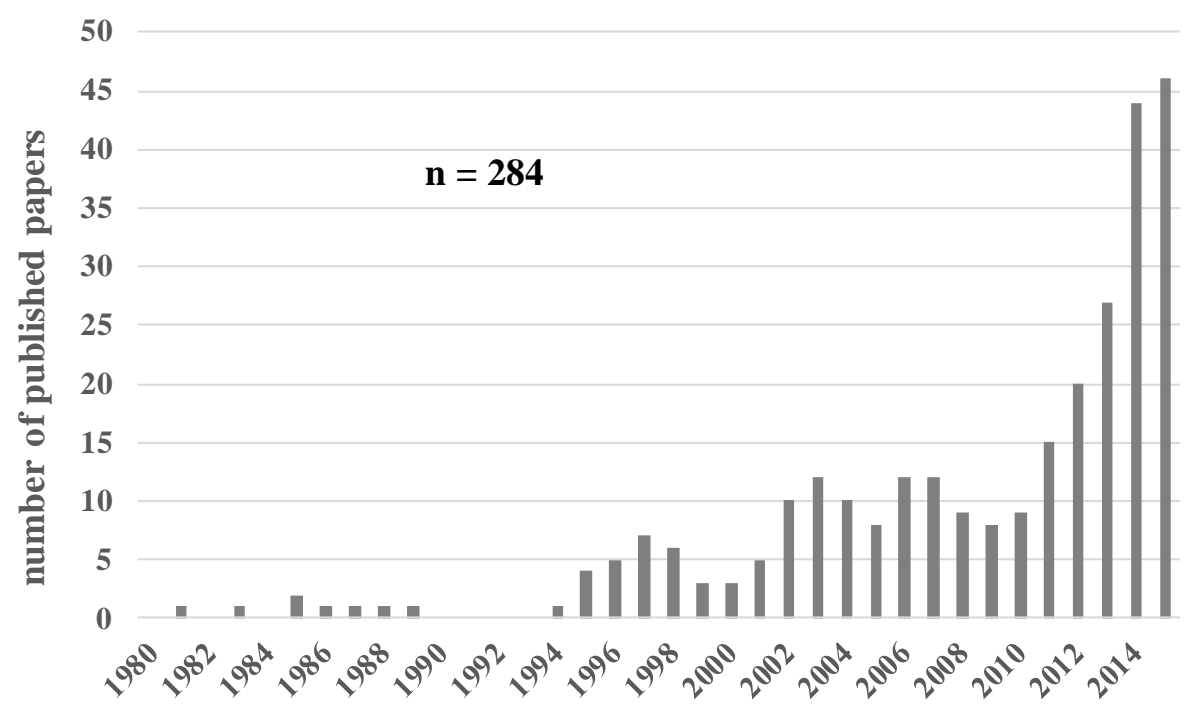

Figure 1. Number of published papers where "Hydropeaking" has been investigated and explicitly mentioned (database: ISI web of science).

The present special issue has been conceived under the awareness that the dynamics of hydropeaking and its sustainable management strategies need to be grounded where the above four spheres of the total environment meet and overlap. It has been proposed also in response to the lack of a wholly dedicated scientific volume or journal issue to the theme of hydropeaking so far at an international level, in a time when research on hydropeaking has developed at a strongly accelerated pace compared to previous decades and also to the global increase in scientific outputs (Figure1; database: webofscience.com). In the first years of hydropeaking research (1981 -1989) 8 studies have been focusing on hydropeaking, followed by 26 studies in 1990 - 1999. In contrast, the period 2000 - 2009 exhibited already 89 scientific studies which contained 'hydropeaking', in the title, abstract or presented results. This trend, however, might be attributed to the overall increase of scientific production: an estimate of Bornmann and Mutz (2014) suggest an average yearly increase rate of overall scientific outputs of $8-9 \%$, which would result in the trend illustrated by the black line in Figure 1, taking the early 1980s as a starting point for hydropeaking research. The same does not seem to apply for the number of hydropeaking papers (161) that have been listed for the period $2010-2015$, a number that largely outpaces the global trend. This suggests that hydropeaking research is recently witnessing a very strong, unprecedented effort from several groups in Europe and worldwide. Not only the abundance but also the composition of hydropeaking research is changing, with early studies (1980s) almost exclusively having a biological-ecological focus, followed by the appearance of hydro-morphological investigations in the mid-1990s and of managementoriented analysis in the early 2000 s. 
Such effort is directed to improve basic knowledge in terms of process understanding, to increase management capacity in terms of the design and testing of suitable mitigation measures, and to strengthen the linkages between basic knowledge and practical applications.

The specific aims of this proposed special issue on "Hydropeaking" is to synthesize present basic and applied research efforts related to hydropeaking. In total, 16 research papers have been accepted in this special issue in terms of field-based, experimental, modeling and integrated approaches, as well as in terms of meta-analysis, regional-scale synthesis, lessons learned from testing of innovative mitigation measures.

\section{Summary of contributions to the Special Issue}

In this special issue the published papers address various hydropeaking topics at different river scales from an improved process understanding to the implementations of mitigation measures. The published papers are divided into five major groups: (i) improved process understanding and biotic response, (ii) advances in modelling tools and extended methods in hydropeaking analysis, (iii) new conceptual approaches for hydropeaking management, (iv) mitigation measure design and practical experiences, and (v) socio-environmental interactions related to hydropeaking. In the first and second groups a total number of six paper per group is listed. Group four, dealing with the design and implementation of mitigation measures contains two primary research papers. For both, group three and five one contribution is listed in this special issue.

Groups one and two have their main focus on process understanding and methods of analysis and prediction; this said, several of them explicitly discuss the implications of their findings in terms of hydropeaking mitigation measures. Group three contains only one paper, which bridges process-understanding contributions of groups one and two with management-oriented papers belonging to groups four and five.

\section{(i) Hydropeaking process understanding and biotic response}

The papers in this first group are based on detailed investigations of hydropeaking processes and biotic responses from a small (patch) scale (Schülting et al., 2016; Auer et al., 2016; CasasMulet et al., 2016; Leitner et al., 2016) up to local scale and reach scale assessment (Capra et al., 2016; Pulg et al., 2016). The patch-scale analyses are carried out on studies in an artificial outdoor research facility for macroinvertebrates (Schülting et al., 2016) and fish (Auer et al., 2016) as well as on field investigations (Casas-Mulet et al., 2016; Leitner et al., 2016). Three papers focus on fish (Auer et al., Capra et al., Casas-Mulet et al.), two on macroinvertebrates (Schülting et al., Leitner et al.) and one on a completely new chemical-physical feature of hydropeaking (Pulg et al.)

The study of Pulg et al. (2016) addresses a completely novel phenomenon related to hydropeaking. During their monitoring of total dissolved gas (TDG) saturation in the Vetlefjordelva River in western Norway in 2014-2015, characteristic waves of supersaturated water were discovered. These waves were significantly correlated with hydropower operation, which was run by hydropeaking. The term "saturopeaking" is introduced for these waves, defined as the artificial, rapid, periodic and frequent fluctuation of gas saturation caused by hydropeaking. While the observed saturation levels were not harmful for the biota, higher values with potentially lethal effects may occur in other streams. Most importantly, this study emphasizes the multi-dimensional nature of hydropeaking and addresses one of the still unexplored dimensions.

Leitner et al. (2016) perform a hydropeaking impact assessment on macroinvertebrates in the Ziller River catchment in Austria. The paper addresses the key issue related to the poor responsiveness of most biological indicators to hydromorphological pressures, like 
hydropeaking. At each sampling reach the Multi-Habitat-Sampling (MHS) method with a Water Framework Directive (WFD) compliant AQEM/MHS net according to the Austrian guideline was performed, together with a hydraulic-specific measuring of abiotic parameters like mean ( $\mathrm{V}_{40}$ ) and bottom-near (Vbottom) flow velocity, water depth, grain size classes. Though stretches, the WFD compliant method mostly did not respond to hydropeaking alteration, suggesting the need to develop a stressor-specific sampling design and to use information on habitat suitability for selected species for mitigation measure design.

Schülting et al. (2016) assessed the single and combined effects of hydropeaking and cold thermopeaking on the drift of selected aquatic macroinvertebrates in experimental flumes in Austria, complementing findings from previous studies. The study shows significantly higher drift rates under hydropeaking during night compared to daytime, also in combination with thermopeaking. Lower drift rates following hydropeaking were found for rheophilic and interstitial taxa, whereas many limnophilic taxa, adapted to slower flows, showed markedly increased drift.

Casas-Mulet et al. (2016) have investigated the very early life stages of fish during dewatering of salmon spawning redds, with alevins having lower tolerance to dewatering than the eggs. These critical life stages have been investigated under hydropeaking through a set of modelling tools that also allow to predict the impacts of mitigation options. The effects of longterm hydrological and thermal alterations on development rates and the mortality risk of early life stages are predicted, and the cost-effectiveness of implementing three release-related mitigation options is assessed. Targeted environmental flow releases may be more costeffective than operational rules complying with existing legislation, and the method is particularly suitable for data-limited case studies.

In Auer et al. (2016) hydropeaking experiments during late summer 2013 with juvenile European grayling (Thymallus thymallus) were conducted in a nature-like experimental channel. They focus on the effect of time of day on the relative drift and stranding rates for a single hydropeaking event on a homogenous gravel bank, with and without potholes simulating potential traps during dewatering. Low drift and stranding rates were observed in dewatering potholes, where nighttime drift rates were about three times and stranding rates about ten times higher compared to the homogenous gravel bank. Importantly, a lowered down-ramping rate reduced drift to about a quarter and almost eliminated nocturnal stranding risk.

Capra et al. (2016) analyzed fish microhabitat selection in modelled heterogeneous hydraulic and thermal conditions of a hydropeaking reach of the large Rhône River in France, locally warmed by the cooling system of a nuclear power plant. Modern fixed acoustic telemetry techniques is used to survey 18 fish individuals (signaling their position every $3 \mathrm{~s}$ ) over a three months' period. Fish habitat selection was investigated depended on combinations of present microhabitat hydraulics (e.g. velocity, depth), past microhabitat hydraulics (e.g. dewatering risk or maximum velocities during the past 15 days), substrate and temperature. Fish individuals appear to memorize spatial and temporal environmental changes and to adopt a "least constraining" habitat selection. When discharge decreases fish select higher velocities but avoid both dewatering areas and very fast-flowing midstream habitats. The study demonstrates temporal variations in habitat selection, depending on individual behavior and environmental history.

\section{(ii) Modelling tools and integrated methods for hydropeaking analysis}

The second group of papers deals with modelling and analytical tools to detect, investigate and predict hydropeaking impacts. The published papers include hydrological assessment and characterization of hydropeaking waves (Alonso et al., 2016), retention effects and downstream changes of ramping velocities based on one-dimensional hydrodynamic-numerical (HN) 
modelling (Hauer et al., 2016), the role of variable roughness in two-dimensional depthaveraged HN-modelling (Kopecki et al., 2016) and the advantages of three-dimensional HNmodelling in terms of hydropeaking assessment (Pisaturo et al., 2016). Moreover, integrative approaches linking hydropeaking disturbances of the physical environment to biotic responses have been examined by Holzapfel et al., (2016) in an extended predictive micro-habitat modelling approach for drift feeding fish as well as for modelling population dynamics for the Atlantic Salmon by Sauterleute et al., (2016). Five out of six papers in this group are based on various modelling approaches, especially hydraulic modelling, in some cases integrated with biological models.

Alonso et al. (2016) proposes an innovative graphical approach to allow a simultaneous identification of hydrological alterations associated with hydropeaking flow regime alterations at multiple time scales. The magnitude, timing and frequency of occurrence of classified values of descriptive, ecologically-relevant hydrological indices can be represented in a map-like graph where longitude, latitude and altitude represent the Julian day, the value of the variable and the frequency of occurrence, respectively. The authors show the ability of the method to provide a comprehensive information on hydropeaking flow alteration by applying it on pairs of free flowing and hydropeaking rivers.

In Hauer et al. (2016) the longitudinal changes of hydropeaking impacts based on retention processes have been investigated, based on unsteady 1D and 2D depth averaged modelling, to investigate possible changes in vertical ramping velocity associated with possible mitigation measures at the local scale. On the first five kilometers downstream of the turbine outlet a significant decrease in vertical ramping velocity occurs. Here, habitat improvements should focus on increasing retention processes considering the higher risk of stranding for juvenile fish and macroinvertebrates. Moreover, at the local scale, self-formed, near-natural morphology should be preferred to artificial sheltering habitats in the design of mitigation measures.

Kopecki et al., (2016), applies vertical velocity profiles in the roughness sub-layer of openchannel flows to derive a depth-dependent roughness formulation for $2 \mathrm{D}$, depth-averaged hydraulic models. This allows considerable improvements in the accuracy of stationary and transient hydrodynamic simulations in shallow river areas. This has particular relevance for predictions of steady habitat conditions and of ramping velocity related to hydropeaking. The roughness sublayer thickness can be kept as a single calibration parameter for the entire range of hydropeaking discharges, thus suggesting the robustness of the chosen formulation. The approach was validated on a $7.5 \mathrm{~km}$ stretch of a middle-size hydropeaking gravel-bed river.

Pisaturo et al. (2016) explore differences between 2D and 3D hydrodynamic models as input for microscale habitat modelling (CASiMiR) used for hydropeaking impact assessment. In the presented case study, habitat simulations using near-bed flow velocities from 3D modelling suggest that suitable habitats might be found over the entire flow range covered by hydropeaking, while predicted habitat availability resulting from 2D modelling is continuously decreasing with increasing flow rates. Model outcomes are validated through laboratory and field observations

Holzapfel et al. (2016) evaluate effects of artificial flow fluctuations on potential epibenthic feeding grounds by simulating overlaps between fish (prey-feeders) and macroinvertebrate (prey) habitats and its possible vulnerability to highly unsteady flow processes. Changes in habitat distribution resulting from rapid flow fluctuations in river reaches with different river morphological characteristics, for five different macroinvertebrate taxa have been investigated. Feeding from the benthos for juvenile and sub-adult brown trout is inhibited during peak flow and reduced during base flow. Potential benthic feeding areas occurring at base flow have been found to increase with the level of morphological heterogeneity, coherently with previous studies.

A novel model integration combining hydraulic-based "fish stranding" into an Atlantic salmon population model has been proposed by Sauterleute et al. (2016) to evaluate long-term 
effects on the population in the Dale River, Western Norway. The sensitivity of the stranding model to different methods to predict dewatered area is assessed, as the main abiotic input parameter to the population model. The largest negative effect on the population abundance for hydropeaking occurred during winter daylight. Salmon smolt production had highest sensitivity to the stranding mortality of older juvenile fish, suggesting that stranding of fish at these life stages is likely to have greater population impacts than that of earlier life-stages.

\section{(iii) New conceptual approaches for hydropeaking management}

A new conceptual framework developed by Bruder et al. (2016) was outlined to support the ecological evaluation of hydropeaking mitigation measures and has been developed based on current mitigation projects in Switzerland and the existing scientific literature. The presented framework is related to a set of indicators that can be predicted quantitatively, and cover all hydrological phases of hydropeaking and the most important affected abiotic and biotic processes. The approach allows a comparison of hydropeaking effects among alternative mitigation measures, to the pre-mitigation situation, and to reference river sections. Key issues include the spatial and temporal context of mitigation projects, the interactions of river morphology with hydropeaking effects, and the role of appropriate monitoring to evaluate the success of mitigation projects. This paper can be viewed as a bridge between the papers of the previous two groups with the management-oriented papers of the following groups.

\section{(iv) Mitigation measure design and practical experiences}

Tonolla et al. (2016) develop an efficient procedure for the ecological evaluation of the impacts of hydropeaking mitigation alternatives in a case study in the Swiss Alps (hydropower company Kraftwerke Oberhasli AG) Various scenarios were evaluated using 12 biotic and abiotic indicators. Despite uncertainties in the ecological responses and the future operation mode of the hydropower plant, the analysis identifies the most appropriate mitigation measure. It combines a basin and a cavern, allowing for substantial dampening in the flow falling and ramping rates and, in turn, considerable reduction in stranding risk for juvenile trout and in macroinvertebrate drift. This measure also allows more specific seasonal regulations of retention volume during ecologically sensitive periods (e.g. fish spawning seasons).

A hydropeaking mitigation project in Valsura torrent (hydropower company Alperia SpA), is described by Premstaller et al. (2016) and represents one of the first examples of this kind in Italy. Based on deficit analysis, a multi-purpose project is developed consisting of a combination of operational and constructive mitigation measures. The measure effectively combines the positive effects of ecological improvement, by maintaining the requested target limits for fish reproduction and reducing macroinvertebrate stress, with higher safety standards and more flexible energy production. This is achieved based on allowing water releases for agricultural irrigation and enhancing flexibility of the plant's energy production in consideration of recreational purposes and related safety issues.

\section{(v) socio-environmentalinteraction related to hydropeaking}

Carolli et al. propose a method to quantify the spatially and temporally distributed suitability of a river reach for whitewater rafting, and apply it to the hydropeaking Noce River in NE Italy, that ranked in the world top 10 for whitewater rafting according to National Geographic. The methodology integrates hydrological, hydraulic and habitat modelling, relying on interviews with local rafting guides to build the rafting preference curves. Hydrological modelling coupled with the allows to assess the effect of hydropeaking along a nearly $30 \mathrm{~km}$ reach even if working with daily flow data. A Rafting Hydro-Suitability Index is developed and used to assess the effect on rafting suitability of planned water abstractions for run-of-the river hydropower plants. While the river would be naturally suitable for rafting in late spring and early summer, artificial peak flows are often needed to sustain rafting in late summer, adding to the complexity of 
multipurpose river management under hydropeaking conditions. In this context, abstraction from run-of-the-river small hydropower plants may have severe negative effects on recreational river use.

\section{Concluding remarks and future research perspectives}

Since almost 35 years hydropeaking and its effects on river (eco)systems have been addressed by scientific research, following a growing trend of scientific outputs which - in the last five years - has largely outpaced the global average of the increase in scientific outputs. We suggest two complementary reasons for this recent increase.

On one side, the enhanced interest is certainly due to the growing regulatory requirements to develop appropriate measures to improve the ecological status, or the ecological potential of regulated rivers in many different countries. For hydropeaking rivers, this has motivated the need to respond to existing knowledge gaps about the complex array of bio-chemical-physical processes affected by hydropeaking (Figure 2). Better understanding of these processes is a key prerequisite to design ecologically effective mitigation measures.

On the other side, however, we suggest that the recent boom in hydropeaking research probably reflects a broader relevance of the multidimensional river processes covered by these investigations for the understanding of river systems and of its components as a whole, (Figure 2 ), even beyond the specific, practical needs of designing and assessing hydropeaking mitigation measures.

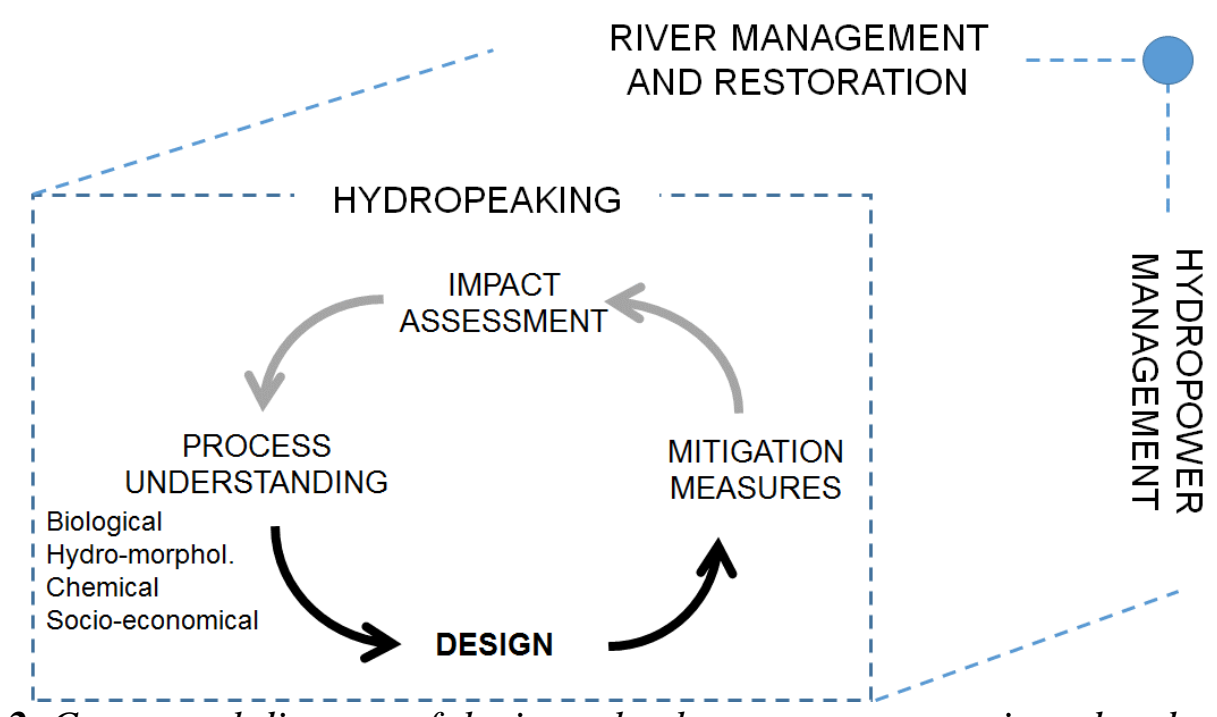

Figure 2. Conceptual diagram of the interplay between process-oriented and managementoriented research on hydropeaking viewed as part of the broader context of river and hydropower management.

The present state of science related to hydropeaking is viewed by the guest editors of this Special Issue as illustrated in Figure 2. Research is presently rather mature (though not conclusive) on topics related to the bottom half of the diagram (arrows and text in black), reflecting the paradigm chosen for the special Issue title ("from process understanding to design of mitigation measures"). This also finds support from the type of papers published in the Special Issue, where three papers (groups three and four) explicitly focus on the design of mitigation measures, but several others in groups one and two clearly mention the relevance of their results in this respect. Process understanding has greatly advanced especially in relation to fish, macroinvertebrates and to some extent, to hydro-morphology (group 1), but the 
interactions of hydropeaking with several components of the whole river signature on the landscape (Gurnell et al., 2016) have still received very limited and insufficient attention. These include riparian vegetation, sediment transport, sediment bed composition (armoring or clogging of river beds) and related effects on morphological changes in rivers, as well as with the riparian and hyporeic aquifers. Moreover, research published in the present special issue suggest that advanced and effective tools are presently available to support the design of mitigation measures, including predictive, quantitative modelling. Hydraulic modelling research, for instance, has been rapidly evolving and targeted applications to compute hydropeaking-relevant physical quantities presently allow assessing the accuracy and adequateness of their management-oriented use. These tools should be helpful to address specific aspects of hydropeaking impacts (e.g quantification of stranding risk) in the framework of multi-stressed river systems (e.g. flood protection, disturbed sediment regime) in future.

We argue that, in the next decades, research shall learn from the monitoring of the effects of mitigation measures, once their actual implementation and management will be more widespread and once enough time has passed since their implementation to allow assessing their consequences at the proper spatial and time scales (grey arrows and text in Figure 2). In this respect, it is highly recommended that accurate short and mid-term monitoring plans will be designed and operated to detect the responses of river biota (e.g. fish, macroinvertebrates, riparian and aquatic vegetation), on the physical environment (e.g. changes in flow patterns / sediment dynamics, channel morphology). This is a particular challenge, given the paucity of targeted monitoring plans associated with river restoration projects so far in alpine and other regions of the world (e.g., Bernhardt et al., 2005, Habersack et al., 2011).

We conclude by highlighting that, while hydropeaking research has been focused so far in a rather limited set of alpine countries, or industrialized countries with relevant hydropower production, future research on hydropeaking may broaden in the near future to different geographical areas in the developing world, given the recent boom in large hydropower project worldwide (Zarfl et al., 2015), their anticipated ecological effects (Winemiller et al., 2016) and the increasing push for a global science for environmental flows (Poff and Schmidt, 2016).

\section{References:}

Alonso, C., Román, A., Dolores Bejarano, M., de Jalon, D.G., Carolli, M. 2016. A graphical approach to characterize sub-daily flow regimes and evaluate its alterations due to hydropeaking. Science of The Total Environment.

Auer, S., Zeiringer, B., Führer, S., Tonolla, T., Schmutz, S. 2016. Effects of river bank heterogeneity and time of day on drift and stranding of juvenile European grayling (Thymallus thymallus L.) caused by hydropeaking. Science of The Total Environment.

Bernhardt, E. S., Palmer, M. A., Allan, J. D., Alexander, G., Barnas, K., Brooks, S., ... \& Galat, D. 2005. Synthesizing US river restoration efforts. Science, 308(5722), 636-637.

Bornmann, L., \& Mutz, R. (2015). Growth rates of modern science: A bibliometric analysis based on the number of publications and cited references. Journal of the Association for Information Science and Technology, 66(11), 2215-2222.

Bruder, A., Tonolla, D., Schweizer, S. P., Vollenweider, S., Langhans, S. D., \& Wüest, A. 2016. A conceptual framework for hydropeaking mitigation. Science of The Total Environment.

Carolli, M., Zolezzi, G., Geneletti, D., Siviglia, A., Carolli, F., Cainelli, O. 2016. Modelling whitewater rafting suitability in a hydropower regulated Alpine River. Science of The Total Environment.

Capra, H., Plichard, L., Bergéa, J., Pella, H., Ovidio, M., McNeil, E. Lamouroux, N. 2016. Fish habitat selection in a large hydropeaking river: strong individual and temporal variations revealed by telemetry. Science of The Total Environment. 
Casas-Mulet, R., Saltveit, S.J., PhD; Alfredsen, K.T. 2016. Effects of hydropeaking on salmonid gravel stages: a modelling approach for implementing mitigation strategies. Science of The Total Environment.

Gurnell, A. M., Bertoldi, W., Tockner, K., Wharton, G., \& Zolezzi, G. 2016. How large is a river? Conceptualizing river landscape signatures and envelopes in four dimensions. Wiley Interdisciplinary Reviews: Water, 3(3), 313-325.

Habersack, H., Piegay, H., \& Rinaldi, M. (Eds.). (2011). Gravel Bed Rivers 6: From Process Understanding to River Restoration (Vol. 11). Elsevier.

Hauer, C., Holzapfel, P., Leitner, P., Graf, W. 2016. Longitudinal assessment of hydropeaking impacts on various scales for an improved process understanding and the design of mitigation measures. Science of The Total Environment.

Holzapfel, P., Leitner, P., Habersack, H., Graf, W., Hauer, C. 2016. Evaluation of hydropeaking impacts on the food web in alpine streams based on modelling of fish- and macroinvertebrate habitats. Science of the Total Environment.

Leitner, P., Hauer, C., Graf, W. 2016. Habitat use and tollerance levely of macroinvertebrates concerning hydraulic stress in hydropeaking rivers - a case study at the Ziller river in Austria. Science of the Total Environment.

Pisaturo, G.R., Righetti, M., Noack, M., Schneider, M., Dumbser, M., Cavedon, V. 2016. The role of 3D-hydraulics in habitat modelling of hydropeaking events. Science of The Total Environment.

Premstaller, G., Cavedon, V., Pisaturo, G. R., Schweizer, S., Adami, V., Righetti, M. 2016. Hydropeaking mitigation project on a multi-purpose hydro-scheme on Valsura River in South Tyrol/Italy. Science of The Total Environment.

Poff, N.LR., Schmidt J.C. 2016. How dams can go with the flow. Science, 353(6304), 1099-1100.

Pulg, U., Vollset, K.W., Velle, G., Stranzl, S. 2016. First observations of saturopeaking: characteristics and implications. Science of The Total Environment.

Sauterleute, J. F., Hedger, R. D., Hauer, C., Pulg, U., Skoglund, H., Sundt-Hansen, L. E., Bakken, T.H., Ugedal, O. 2016. Modelling the effects of stranding on the Atlantic salmon population in the Dale River, Norway. Science of The Total Environment, 573, 574-584.

Schülting, L., Feld, C.K., Graf, W. 2016. Effects of hydro- and thermopeaking on benthic macroinvertebrate drift. Science of the Total Environment.

Tonolla, D., Bruder, A., Schweizer, S. 2016. Evaluation of mitigation measures to reduce hydropeaking impacts on river ecosystems - a case study from the Swiss Alps. Science of The Total Environment.

Winemiller, K. O., McIntyre, P. B., Castello, L., Fluet-Chouinard, E., Giarrizzo, T., Nam, S., ... \& Stiassny, M. L. J. 2016. Balancing hydropower and biodiversity in the Amazon, Congo, and Mekong. Science, 351(6269), 128-129.

Zarfl, C., Lumsdon, A. E., Berlekamp, J., Tydecks, L., \& Tockner, K. 2015. A global boom in hydropower dam construction. Aquatic Sciences, 77(1), 161-170. 